\title{
Tumor Results Original Result Unit
}

National Cancer Institute

\section{Source}

National Cancer Institute. Tumor Results Original Result Unit. NCI Thesaurus. Code

C117417.

The unit of measure for the result of the tumor results assessment as originally received or collected. 